九州大学学術情報リポジトリ

Kyushu University Institutional Repository

\title{
Laser power dependence of particulate formation on pulse laser deposited films
}

Watanabe, Yukio

Mitsubishi Chemical Yokohama Research Center

Tanamura, M.

Mitsubishi Chemical Yokohama Research Center

Matsumoto, Y.

Mitsubishi Chemical Yokohama Research Center

Seki, Y.

Mitsubishi Chemical Yokohama Research Center

http://hdl. hand le. net/2324/4493206

出版情報 : Journal of Applied Physics. 78 (3), pp.2029-2036, 1995-08-01. American Institute of Physics

バージョン :

権利関係 : ๑ 1995 American Institute of Physics 


\section{Laser power dependence of particulate formation on pulse laser deposited films}

Cite as: Journal of Applied Physics 78, 2029 (1995); https://doi.org/10.1063/1.360179

Submitted: 03 February 1995 . Accepted: 13 April 1995 . Published Online: 04 June 1998

Yukio Watanabe, M. Tanamura, S. Matsumoto, et al.

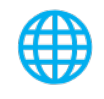

\section{ARTICLES YOU MAY BE INTERESTED IN}

Compositional distribution of laser-deposited films and rapid sequential pulsed laser deposition

Journal of Applied Physics 78, 5126 (1995); https://doi.org/10.1063/1.359744

Challenge us. What are your needs for periodic signal detection?

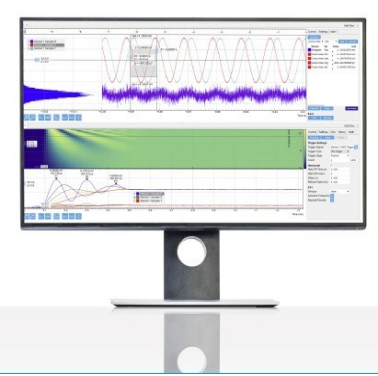

Zurich

Instruments 


\title{
Laser power dependence of particulate formation on pulse laser deposited films
}

\author{
Yukio Watanabe, ${ }^{\text {a) }}$ M. Tanamura, S. Matsumoto, and Y. Seki \\ Mitsubishi Chemical Yokohama Research Center, Yokohama 227, Japan
}

(Received 3 February 1995; accepted for publication 13 April 1995)

\begin{abstract}
The density and the size of particulates in films laser-deposited at room temperature using various target materials were observed to depend strongly on the target material and the laser power density. However, loose universal relations between the deposition rates and the particulate density as well as the particulate size were found, where the latter corresponds approximately to the ratio of the laser power density to the ablation threshold. Furthermore, particulates consisting of only some of the target elements such as $\mathrm{CuOx}$ were found. Additionally, an acceptably high deposition rate was obtained by using halide and sulfide targets. These materials offer a possibility of deposition using a low power laser. (C) 1995 American Institute of Physics.
\end{abstract}

\section{INTRODUCTION}

Pulse laser deposition (PLD) has been regarded as a versatile method to grow ceramic thin films. ${ }^{1}$ However, despite local flatness, ${ }^{2}$ particulate formation has been observed in some films such as $\mathrm{YBa}_{2} \mathrm{Cu}_{3} \mathrm{O}_{7}$ (YBCO). ${ }^{3}$ Although its origin is complicated and has not yet been fully understood, it is a generally accepted view that particulate formation is affected by the target material, the target surface morphology, the target density, and the laser power density.

Two kinds of particles in laser deposited films have been reported: Particulates, boulders, or droplets which usually have rounded shapes and the same composition as the film matrix. ${ }^{3-8}$ Precipitates or outgrowths which have a composition different from the film matrix. ${ }^{5-9}$ Precipitates were observed in films grown by virtually all deposition methods such as sputter deposition ${ }^{10,11}$ or metalorganic chemical vapor deposition. ${ }^{12}$ Although particulates are easily reduced to a certain density, e.g., one per $100 \mu \mathrm{m}^{2}$ for a $1000-\hat{A}$-thick YBCO film, by controlling the target surface condition, particulate elimination has not been achieved with conventional PLD, except some special versions. ${ }^{7,13}$ On the other hand, reduction or elimination of the precipitates number density and their size has been achieved well by optimizing growth conditions.

Whether particulates or precipitates are the dominant particles on the film depends on the deposition conditions. The particulates are observed to reduce at a low laser power density (LPD), e.g., $\sim 1 \mathrm{~J} / \mathrm{cm}^{2}$ for $\mathrm{YBCO} .{ }^{14,15}$ However, the use of such a low LPD usually degrades the film stoichiometry, resulting in growth of precipitates or in surface roughness at temperatures which are suitable to obtain good crystallographic and electrical properties. ${ }^{15}$ Such precipitates were observed to reduce when lowering the substrate temperature $\left(T_{s}\right)$, which causes a slight degradation of the electrical and crystallographic properties. Indeed, there seems to be a trade-off among the particulate density, the precipitate density, and the electrical and crystallographic properties for a given target material. The success of optimization is material dependent.

a)Electronic mail: nabe@rc.m-kasie.co.jp
In case of $\mathrm{YBCO}$, it was difficult to reproducibly reduce the particulate density below one per $0.01 \mathrm{~mm}^{2}$, while keeping the zero-resistance temperature above $80 \mathrm{~K}$ by controlling the LPD. Contrarily, particulate densities of $(\mathrm{La}, \mathrm{Sr})_{2} \mathrm{CuO}_{4}$ and $\mathrm{BaTiO}_{3}$ films reduced easily and reproducibly well below one per $0.01 \mathrm{~mm}^{2}$ without degrading their electrical properties. ${ }^{16}$ These differences are probably due to the difference in the optimum LPD range, where exact stoichiometry and suppression of particulates can be obtained. Since the film stoichiometry is generally known to degrade as the LPD decreases, ${ }^{17}$ we need to know the maximum LPD at which the particulate formation is still suppressed. To study this issue, we have examined films deposited under varying the LPD by using targets having different chemical compositions, namely, halides, sulfides, carbonates, alloys, metals, and oxides. In this paper, particulate density and particulate size in the films deposited using these targets are reported. and the results are summarized in terms of the LPD. An approximate material-independent relation between particulate formation and deposition rate was found.

\section{EXPERIMENT}

Films were deposited on $\mathrm{MgO}(100)$ crystals in a molecular oxygen pressure of 100 mtorr by the PLD method with an ArF excimer laser. The wavelength, the pulse width, and the average repetition rate were $193 \mathrm{~nm}, 10 \mathrm{~ns}$, and $1-10 \mathrm{~Hz}$, respectively. To obtain uniform laser power distribution in the laser spot, laser pulses were focused a little in front of the target after passing through apertures. The laser beam was scanned over the target surface to suppress degradation of the target surface morphology. By changing the focus and the laser power at the source, LPDs at the target were changed between 0.2 and $2 \mathrm{~J} / \mathrm{cm}^{2}$. The substrate was set at $8 \mathrm{~cm}$ from the target, and the substrate holder was kept at about $30^{\circ} \mathrm{C}$ (in a few depositions at $100^{\circ} \mathrm{C}$ ) to eliminate precipitate growth.

Target materials used were $\mathrm{YBCO}$, the compounds containing only one kind of metal element: $\mathrm{YF}_{3}, \mathrm{YCl}_{3}, \mathrm{Y}_{2} \mathrm{O}_{3}$, $\mathrm{Y}_{2} \mathrm{~S}_{3}, \mathrm{BaF}_{2}, \mathrm{BaCl}_{2}, \mathrm{BaF}_{2}-\mathrm{BaCl}_{2}(9: 1), \mathrm{BaCO}_{3}, \mathrm{BaO}, \mathrm{BaS}$, $\mathrm{CuF}_{2}, \mathrm{CuCl}_{2}, \mathrm{CuBr}_{2}, \mathrm{CuO}, \mathrm{Cu}_{2} \mathrm{~S}_{1}$ the compounds containing only two kinds of metal elements as major metal constitu- 


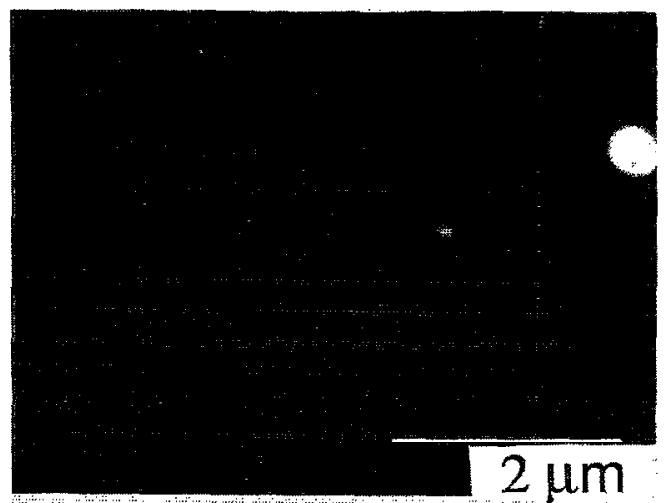

FIG. 1. SEM pictures of $\mathrm{YBCO}$ film on $\mathrm{LaAlO}_{3}(100)$ crystal deposited at $700^{\circ} \mathrm{C}$ using $\mathrm{YBCO}$ sintered target. The particulate at the upper right corner was identified to be CuOx by electron probe micro analysis. The zero resistance of this film was $88 \mathrm{~K}$.

ents: $\mathrm{BaCuO}_{2}, \mathrm{YCuO}_{2.5}, \mathrm{Y}$-doped $\mathrm{BaCuO}_{2}\left(\mathrm{BaCuO}_{2}: \mathrm{Y}\right)$, the metals and the binary alloys: $\mathrm{Y}, \mathrm{Ba}, \mathrm{Cu}, \mathrm{Cu}$-doped $\mathrm{Ba}(\mathrm{Ba}: \mathrm{Cu}), \mathrm{BaCu}, \mathrm{YCu}, \mathrm{YCu}_{3}$, and mechanically formed $\mathrm{YBa}_{2} \mathrm{Cu}_{3}$ powder alloy, which was employed because no solid solution of $\mathrm{Y}, \mathrm{Ba}$, and $\mathrm{Cu}(\mathrm{Y}: \mathrm{Ba}: \mathrm{Cu}=1: 2: 3)$ could be obtained. The density of the sintered targets was maximized either by annealing in a conventional furnace at the optimum temperatures $\left(<1400^{\circ} \mathrm{C}\right)$ at which neither melting nor decomposition occurred, or by partial melting in an infrared furnace. Halide and sulfide targets were annealed in a vacuum sealed ampule to avoid oxidation.

Particulates on each film were examined using an optical microscope as well as a scanning electron microscope (SEM) at magnifications ranging from 100 to 50000 . Compositions of particulates larger than $0.15 \mu \mathrm{m}$ were analyzed by energy dispersive $x$-ray spectroscopy (EDX) installed in the SEM. The particulate number density was obtained by dividing their number counted in SEM pictures by the efrective thickness and the observation area. Here, the effective thickness is defined as total molar number per unit area measured by $\mathrm{x}$-ray fluorescent spectroscopy (XRF). Selected SEM pictures were also analyzed using a computer image processing system to check the results.

\section{RESULTS}

\section{A. YBCO}

We made several attempts to eliminate particulates by changing the composition and the texture of targets. Sintered $\mathrm{YBa}_{2} \mathrm{Cu}_{3} \mathrm{O}_{7}$ targets with a density between $60 \%$ and $97 \%$ of the ideal value, as well as $\mathrm{YBa}_{2} \mathrm{Cu}_{3}$ powder alloy were used. These materials did not show any improvement in the particulate problem. The compositions of the particulates $>5$ $\mu \mathrm{m}$ and $<1 \mu \mathrm{m}$ were mostly $\mathrm{YBa}_{2} \mathrm{Cu}_{3} \mathrm{O}_{x}$ and $\mathrm{CuOx}$, respectively, where the $\mathrm{CuOx}$ particulates (Fig. 1) were considered to come from the target as discussed later. $\mathrm{YBa}_{2} \mathrm{Cu}_{3} \mathrm{O}_{\text {, tar- }}$ gets obtained by partial melting in an infrared furnace had a hard shiny surface, suggesting improved packing of the surface. However, their surface had a high $\mathrm{BaCuO}_{2}$ content. The particulates were reduced in the films deposited using these targets in agreement with Singh et al. ${ }^{18}$ In these films, good

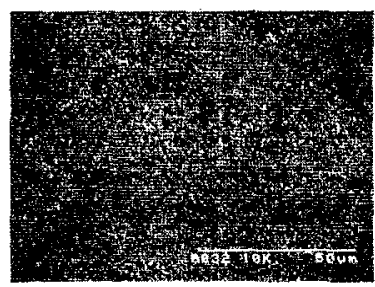

(a)

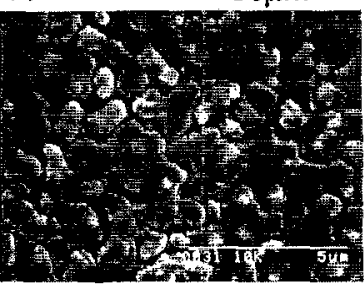

(b) $5 \mu \mathrm{m}$

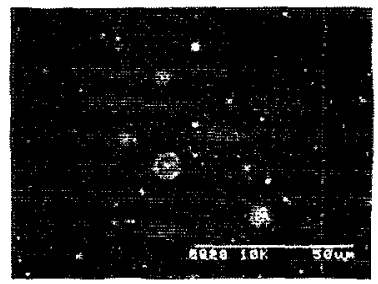

(c) $-50 \mu \mathrm{m}$

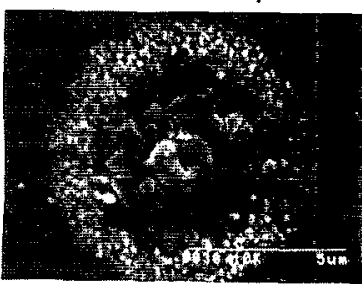

(d) $-5 \mu \mathrm{m}$
FIG. 2. SEM pictures of films deposited at $700^{\circ} \mathrm{C}$ using two kinds of targets: partially melted at $1070^{\circ} \mathrm{C}$ and then quenched (a), (b) (the film composition was $\mathrm{Y}: \mathrm{Ba}: \mathrm{Cu}=1: 5.6: 6.2$ in molar ratio), $\mathrm{YBa}_{2} \mathrm{Cu}_{3}$ powder alloy (c), (d). The avcrage thicknesses of the films are approximately $600 \AA$ (3 $\left.\mu \mathrm{mol} / \mathrm{cm}^{2}\right)$ for (a) and $400 \AA\left(2 \mu \mathrm{mol} / \mathrm{cm}^{2}\right)$ for (c).

electrical properties, precipitate reduction, and particulate elimination were not achieved at the same time, which may be due to the presence of four different elements in the targets. The SEM pictures in Fig. 2 show the surface morphology of films deposited using a partially molten $\mathrm{YBCO}$ target and a $\mathrm{YBa}_{2} \mathrm{Cu}_{3}$ powder-alloy target. The target for Fig. 2(a) was partially molten at $1070^{\circ} \mathrm{C}$ and subsequently quenched. Few particulates, but many precipitates were observed on the film. When target is partially molten at $1030^{\circ} \mathrm{C}$, the size of the precipitates was reduced, but typically one to two particulates were observed in a surface area of $0.01 \mathrm{~mm}^{2}$.

\section{B. Example of deposition rate-dependent particulate formation}

The particulate formation was re-examined using films deposited with targets having simpler compositions. To examine the effect of the melting temperature $\left(T_{m}\right)$, its ratio to the boiling temperature, and the ionicity in chemical bonding of target materials, films were deposited using targets explained previously. No relationship of these properties to particulate properties was observed. Instead, it was generally observed that the smaller the number of different elements in the target was, the easier and the more reproducible was the elimination of particulates by adjusting the LPD.

For a given target material, the density and the size of the particulates were mostly observed to increase as the power density increased. Figures $3(\mathrm{a})-3(\mathrm{e})$ and their magnifications [Figs. 4(a) $-4(\mathrm{e})]$ show such examples. The LPDs on the $\mathrm{BaCu}$ alloy target were $0.3,0.4$, and $1.2 \mathrm{~J} / \mathrm{cm}^{2}$ for Figs. 3(a), 3(b), and 3(c), respectively. Moreover, it was found that by changing the target material at a fixed LPD of $1.2 \mathrm{~J} / \mathrm{cm}^{2}$, the deposition rate as well as the particulate density increased [Figs. 3(d), 3(e), 3(c), and Figs. 4(d), 4(e), 4(c)]. The target materials used were $\mathrm{YCu}, \mathrm{BaCuO}_{2}: \mathrm{Y}$, and $\mathrm{BaCu}$ for Figs. 3(c), 3(d), and 3(e), respectively. These re- 


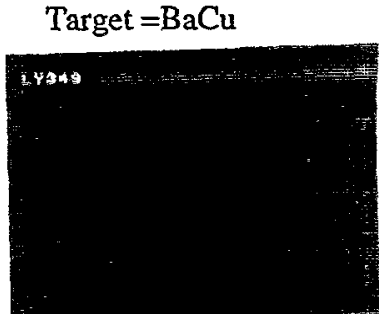

(a) $\mathrm{Pw}=0.3 \mathrm{~J} / \mathrm{cm}^{2}$

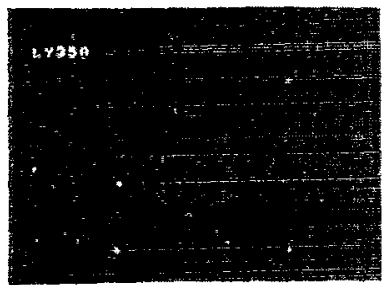

(b) $\mathrm{Pw}=0.4 \mathrm{~J} / \mathrm{cm}^{2}$

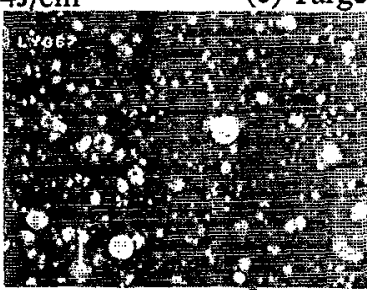

(e) Target $=\mathrm{BaCuO}_{2}: \mathrm{Y}$

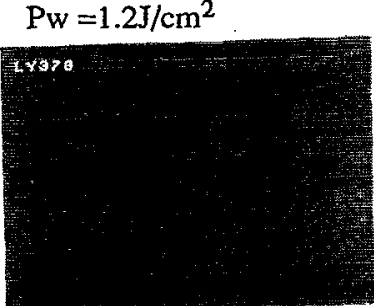

(d) Target $=\mathrm{YCu}$

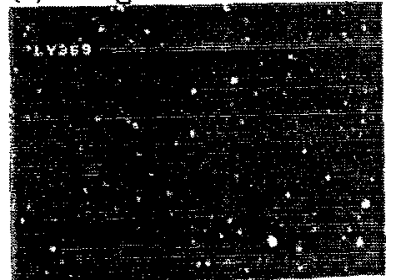

The

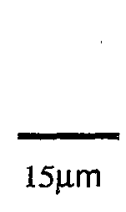

(c) $\mathrm{Pw}=1.2 \mathrm{~J} / \mathrm{cm}^{2}$

Target $=\mathrm{BaCu}$

FIG. 3. SEM pictures showing the dependence of particulate density on deposition rate. In (a), (b), and (e), the power density is changed for a same target material, and target inaterials are changed at a same power density in (c)-(e). The films were deposited at RT. The deposition rates per spot size (nmol $/ \mathrm{cm}^{2} / \mathrm{cm}^{2} / \mathrm{shot}$ ) are $0.1-0.5,1-3$, and $\sim 10$ for (a) (c), (b) (d), and (e), respectively. The effective thicknesses $\left(\mu \mathrm{mol} / \mathrm{cm}^{2}\right)$ were $0.16,0.11,4.89$, 0.24 , and 2.73 for $(\mathrm{a})-(\mathrm{e})$, respectively.

sults suggest a correlation between the particulate formation and the deposition rate, which is discussed below.

\section{The physical meaning of the deposition rate dependence}

According to the relationship between the LPD and the deposition rate, ${ }^{19,20,17}$ the deposition rate in the LPD can be regarded as a measure of the ratio of the LPD to the materialspecific ablation threshold. Namely, we postulate evaporation rate/shot/beam spot area $=$ function $[\mathrm{LPD}$, ablation threshold $\left.\left(E_{\text {th }}\right)\right]$ :

$$
\sim c\left(\mathrm{LPD} / E_{\mathrm{th}}-1\right) \text { for } E_{\mathrm{th}}<\mathrm{LPD}<\infty .
$$

The last expression is based on experimental observations, ${ }^{19,17}$ and $c$ is a material specific constant. Alternatively, the evaporation rate per pulse per area of the beam spot on the target can be regarded as a measure of the ratio of the LPD to the $E_{\text {th }}$. This holds true irrespective to the target materials, if the constant " $c$ " are of the same order. The evaporation rate per shot per beam spot area should scale with the deposition rate per shot per beam-spot area at a given ambient gas pressure and a given target/substrate distance. Therefore, we define this deposition rate as a "normalized deposition rate."

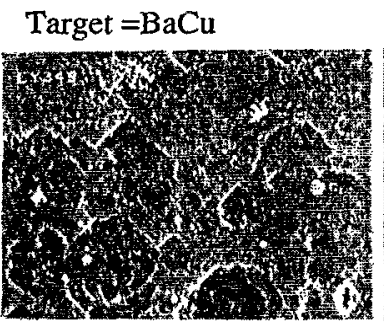

$\mathrm{Pw}=1.2 \mathrm{~J} / \mathrm{cm}^{2}$ (a) $\mathrm{P}_{\mathrm{W}}=0.3 \mathrm{~J} / \mathrm{cm}^{2}$

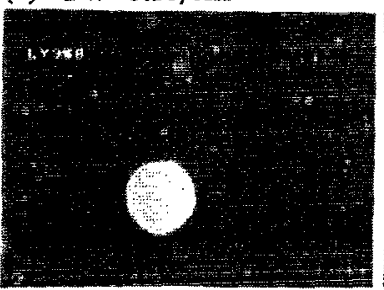

(b) $\mathrm{Pw}=0.4 \mathrm{~J} / \mathrm{cm}^{2}$

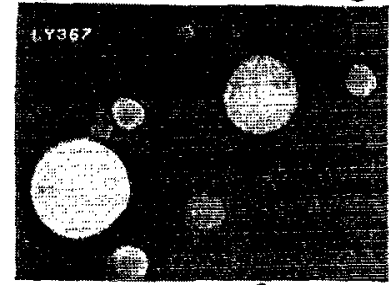

(e) Target $=\mathrm{BaCuO}_{2}: \mathrm{Y}$

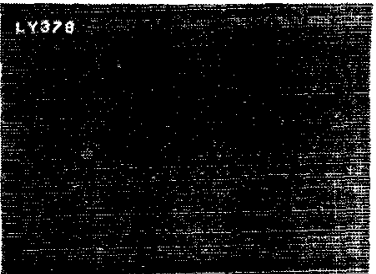

(d) Target $=\mathrm{YCu}$

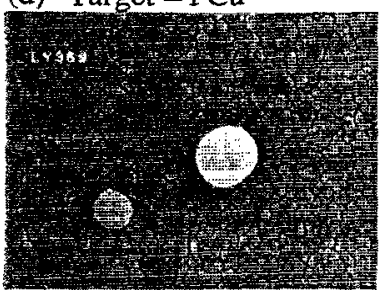

a

$0.6 \mu \mathrm{m}$ (c) $\mathrm{Pw}=1.2 \mathrm{~J} / \mathrm{cm}^{2}$

Target $=\mathrm{BaCu}$

\section{Deposition rate dependence of the particulate number density and the areal occupancy}

Figures $5(\mathrm{a})-5(\mathrm{c})$ show plots of the particulate number density vs the normalized deposition rate for films deposited at various $\mathrm{LPDs}$ using $\mathrm{YCu}\left(\mathrm{YCu}, \mathrm{YCu}_{3}\right), \mathrm{BaCu}(\mathrm{BaCu}$, $\left.\mathrm{Ba}: \mathrm{Cu}, \mathrm{BaCO}_{3}, \mathrm{BaCuO}_{2}\right), \mathrm{BaCuO}_{2}: \mathrm{Y}$, and $\mathrm{CuX}\left(\mathrm{CuO}, \mathrm{Cu}_{2} \mathrm{~S}\right)$ as targets. The plots in Fig. 5 were obtained by visual inspection. The particles were roundly shaped, and their sizes ranged from $0.02 \mu \mathrm{m}$ to a few $\mu \mathrm{m}$ in diameter $(\phi)$. Particulates of a diameter of a few ten $\mu \mathrm{ms}$ were also observed on the films of BaS and $\mathrm{BaCl}_{2}$, which were not plotted in Fig. 5 . Figures 5(a)-5(c) are for particulates $<0.1 \mu \mathrm{m} \phi, 0.1 \sim 0.5$ $\mu \mathrm{m} \phi$, and $0.5 \sim 1 \mu \mathrm{m} \phi$, and $>1 \mu \mathrm{m} \phi$, respectively. Here, the particulate number density was defined as the particulate number per thickness per unit area of $0.01 \mathrm{~mm}^{2}$, where the film thickness and the deposition rate were measured by the molar number per unit area $\left(\mathrm{nmol} / \mathrm{cm}^{2}\right)$. Typically, 1 $\mu \mathrm{mol} / \mathrm{cm}^{2}$ corresponded to a thickness of about $200 \AA$. All particulates, except dust, were counted as particulates, because precipitates of the above compounds were unlikely to grow below $100^{\circ} \mathrm{C}$. The large scatter of the data was partly attributed to an incomplete control of the target surface quality during their preparation and to a change of the target surface during deposition.

Irrespectively of the target materials, particulates $>0.1$ $\mu \mathrm{m}$ in diameter were basically absent at normalized deposition rates $<0.2 \mathrm{nmol} / \mathrm{cm}^{2} / \mathrm{spot}$ area/shot. Therefore, there are only a few data points below that value in Figs. 5(b) and 5(c). Furthermore, as the normalized deposition rate increased, the typical particulate-size increased, and the num- 
(a)

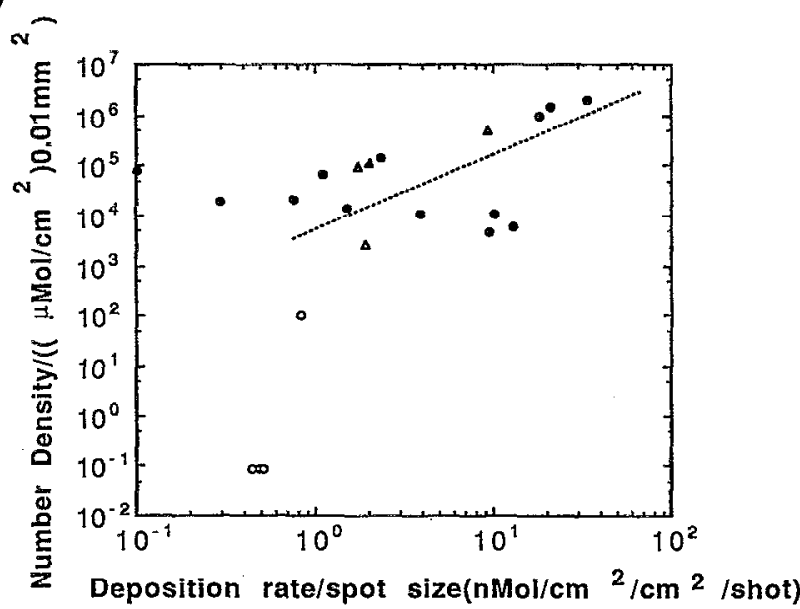

(b)

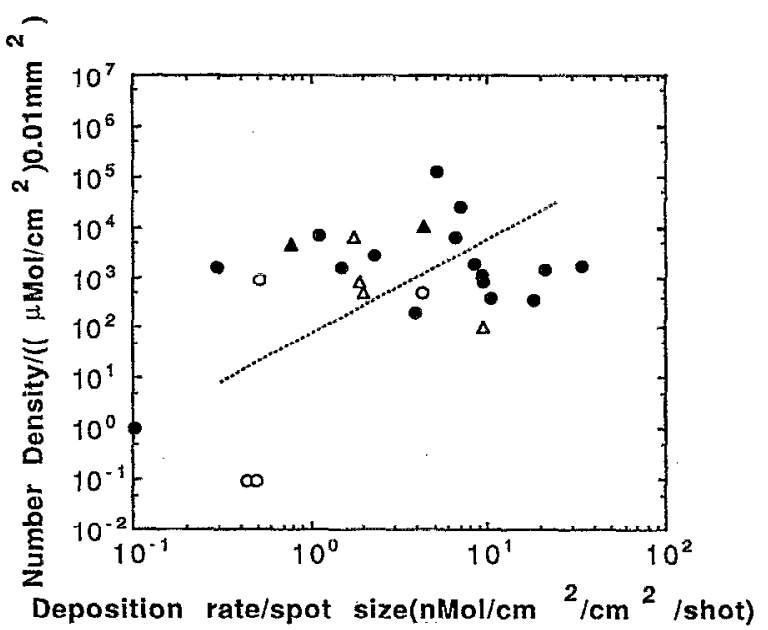

(c)

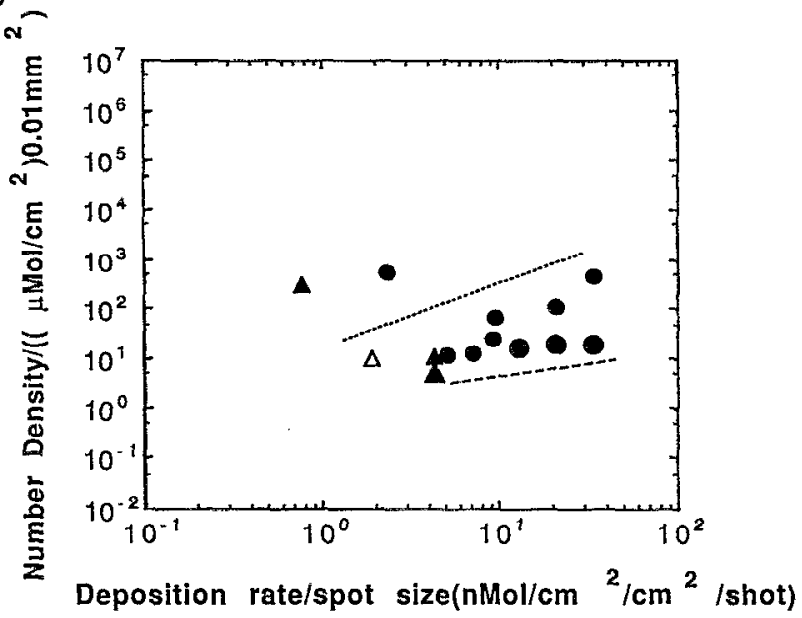

FIG. 5. Dependence of particulate number density on deposition rate per shot per laser spot area (normalized deposition rate). The symbols correspond to targets materials $\mathrm{YCu}, \mathrm{YCu}_{3}(\mathrm{O}), \mathrm{BaCu}, \mathrm{Ba} \mathrm{Cu}, \mathrm{BaCuO}_{2}(\mathrm{O})$, $\mathrm{BaCuO}_{2}: \mathrm{Y}(\triangle), \mathrm{CuO}$ and $\mathrm{Cu}_{2} \mathrm{~S}(\Delta)$. (a)-(c) show the results the different sizes of the particulates $<0.1 \mu \mathrm{m} \phi$ (a), $0.1-0.5 \mu \mathrm{m} \phi$ (b), 0.5-1 $\mu \mathrm{m} \phi$ [smaller symbols in (c)] and $>1 \mu \mathrm{m} \phi$ [larger symbols in (c)] respectively. For a beam with a spot size of $10 \mathrm{~mm}^{2}$, the normalized deposition rate of 1 $\mathrm{nmol} / \mathrm{cm}^{2} / \mathrm{shot}$ is typically $0.02 \AA / \mathrm{shot}$. ber density also tended to increase. The latter result was more evident for a given kind of target material as denoted by specific symbols in Figs. 5(a)-5(c). It should be mentioned that the normalized deposition rate (nmol $/ \mathrm{cm}^{2} / \mathrm{cm}^{2} /$ shot) ranged from 0.01 to 5 for the $\mathrm{YCu}$ target, from 0.1 to 30 for the $\mathrm{BaCu}$ target, from 1 to 10 for $\mathrm{BaCuO}_{2}: \mathrm{Y}$, and from 0.5 to 5 for the $\mathrm{CuX}$ target, respectively. Particulates $>0.1 \mu \mathrm{m} \phi$ were absent on most of the $\mathrm{YCu}$-target films at the same normalized deposition rate at which particulates $>0.1 \mu \mathrm{m} \phi$ were abundantly observed on the films deposited with other targets. On the other hand, particulates up to $0.5 \mu \mathrm{m} \phi$ were observed on $\mathrm{BaCu}$-target films at the same normalized deposition rate at which few particulates $<0.1 \mu \mathrm{m} \phi$ were observed on YCu-target films. It should be emphasized that particulates $>1 \mu \mathrm{m} \phi$ were only observed at high normalized deposition rates without showing material dependency. A number of these results were confirmed by computer processing of SEM pictures. ${ }^{14}$ The correlation between the particulate number density and the normalized deposition rate should be physically the same as the correlation between the particulate number density and the etching rate of the target. ${ }^{21}$

The dependence of the particulate formation on the normalized deposition rate was more evident in the area occupancy of particulates per thickness. In case of visually inspected data, the areal occupancy was calculated as areal occupancy $=\Sigma$ (typical size $\times$ number density) each size category $_{\text {, }}$ where the sum $\Sigma$ was taken over all the size categories. A correlation between the areal occupancy and the normalized deposition rate was evident, as shown in Fig. 6(a). This correlation was confirmed as well using computer processing of selected SEM pictures [Fig. 6(b)]. These results suggest that the normalized deposition rate, or the $\mathrm{LPD} / E_{\text {th }}$ ratio, is an important factor determining the particulate formation.

\section{E. Particulate composition and its relation to bulk phase diagrams}

Three to five typical particulates were analyzed in all films by EDX. When the deposition rate was changed, the particulates shown in Figs. 2(a)-2(e) changed not only their size but also their composition. In Figs. 3(a) and 3(d), the particulates were absent or too small to be analyzed by our EDX. The composition of particulates $>0.5 \mu \mathrm{m} \phi$ was mostly $\mathrm{Ba}$ in Fig. 3(b), mostly $\mathrm{YBa}$ (or $\mathrm{YBa}$ oxides) and $\mathrm{BaCu}$ (or $\mathrm{BaCu}$ oxides) in Fig. 3(e), and mostly $\mathrm{Ba}$ and $\mathrm{BaCu}$ in Fig. 3(c), respectively. It should be noted that the particulate compositions were different from the target composition at a low normalized deposition rate. Contrarily, the majority of the particulates had the same composition as the target at relatively high normalized deposition rates [Fig. $3(\mathrm{c})]$.

Figure 7 shows the composition of the particulates on the films deposited at room temperature (RT) using the $\mathrm{YCu}$, the $\mathrm{BaCu}$, the $\mathrm{BaCuO}_{2}$, and the $\mathrm{BaCuO}_{2}: \mathrm{Y}$ targets. It also shows the dependence of the particulate composition on the normalized deposition rate for a given target. At a low normalized deposition rate, the particulates had a composition different from the target composition. Since these particles were observed on films deposited at RT, it is inappropriate to 
(a)

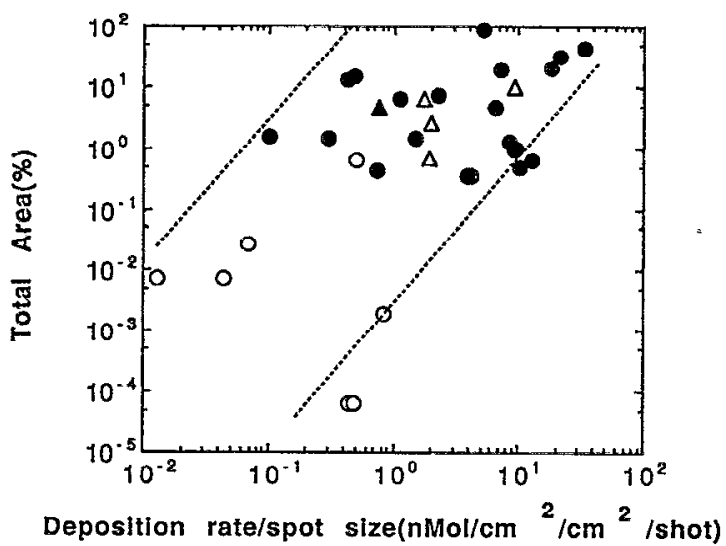

(b)

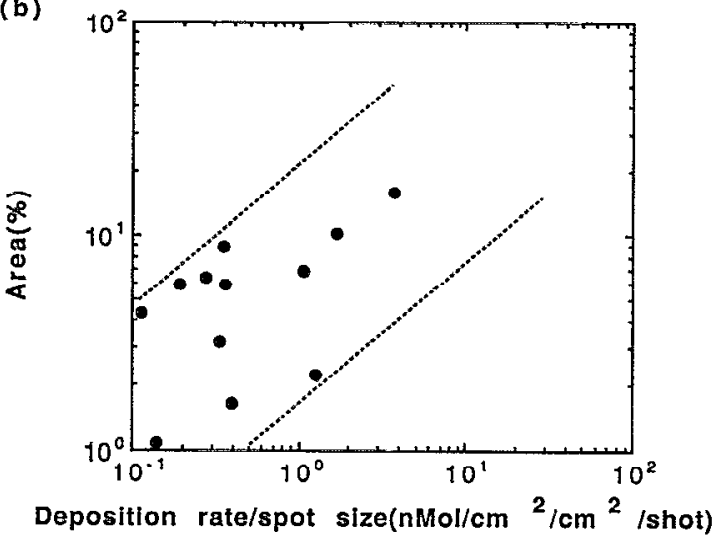

FIG. 6. Dependence of total areal occupancy of particulates on the normalized deposition rate. The meanings of symbols are same as those in Fig. 5. (a) is obtained by the eye inspection, and (b) is obtained by the computer processing of the part of the SEM pictures used in (a).

interpret them as precipitates. According to studies of bulk ceramics, ${ }^{22,23} \mathrm{BaCuO}_{2}$ can be formed from its melt in a thermal equilibrium, unlike $\mathrm{YBCO}$ and $\mathrm{YCu}_{25}$. Moreover, according to binary alloy phase diagrams, ${ }^{24} \mathrm{Ba}$ and $\mathrm{Cu}$ are

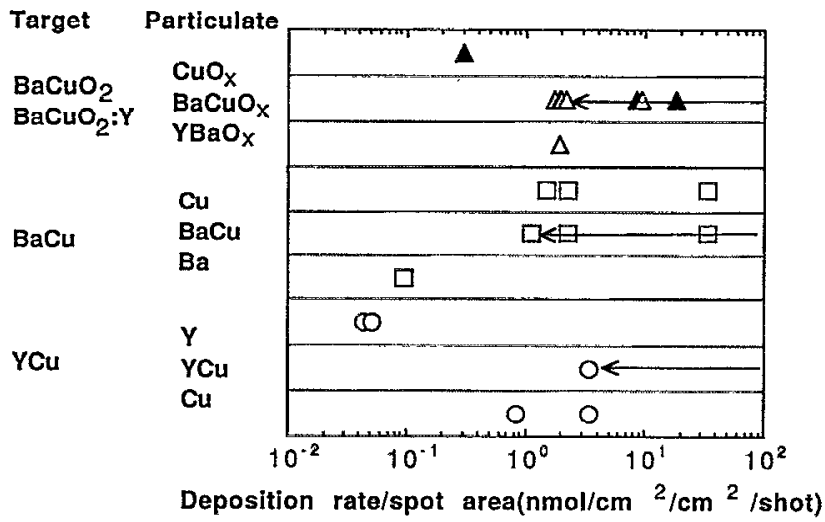

FIG. 7. Composition of the particulates on the $\mathrm{YCu}$, the $\mathrm{BaCu}$, the $\mathrm{BaCuO}_{2}$ and the $\mathrm{BaCuO}_{2}: \mathrm{Y}$ films vs the normalized deposition rate. The symbols indicates the targets used in the deposition: $O(\mathrm{YCu}), \square(\mathrm{BaCu}), \boldsymbol{\Delta}$ $\left(\mathrm{BaCuO}_{2}\right)$, and $\triangle\left(\mathrm{BaCuO}_{2}: \mathrm{Y}\right)$. The first and the second columns show the target composition and the particulate composition of the specific particulate analyzed. The arrows show the possible range where the majority of the particulates should have the same composition as the target. (a)

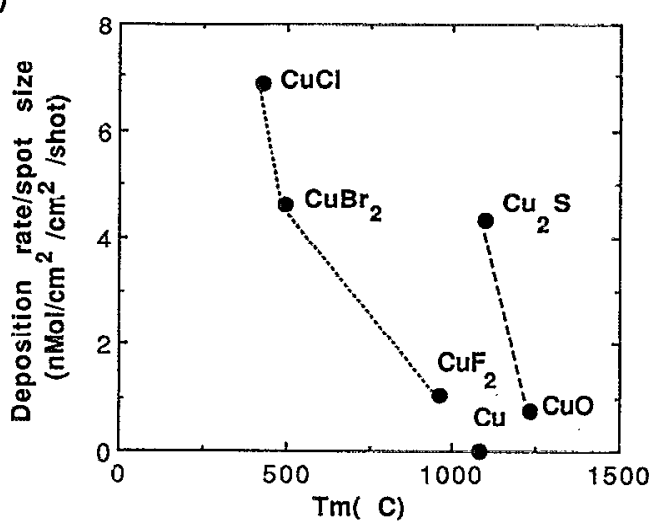

(b)

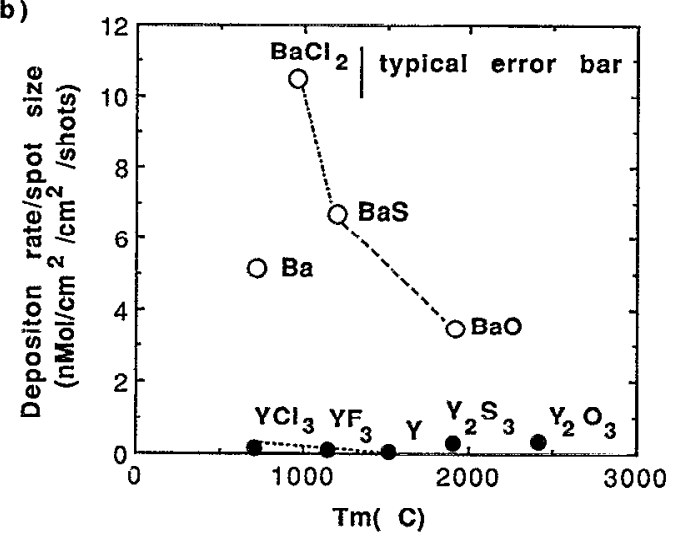

FIG. 8. Deposition rates at a same deposition condition using different targets. The abscissa is $T_{m}$ of each compound. The power density was 0.1 $\mathrm{J} / \mathrm{cm}^{2}$, and the spot size was $0.7 \mathrm{~cm}^{2}$. The amount of only the metal deposits was measured. (a) is for the $\mathrm{Cu}$ compound deposition, and (b) is for the $\mathrm{Y}$ and the $\mathrm{Ba}$ compound deposition.

mutually soluble in all proportions in the liquid phase, and $\mathrm{BaCu}$ with $T_{m} \sim 570^{\circ} \mathrm{C}$ can be directly formed from the melt (i.e., the liquid). $\mathrm{Y}$ and $\mathrm{Cu}$ should also be mutually soluble in all proportions in the liquid phase. However, $\mathrm{YCu}$ $\left(T_{m} \sim 670-830^{\circ} \mathrm{C}\right)$ should not be directly formed from the melt, if we assume a similarity of the phase diagrams of $\mathrm{Y}-\mathrm{Cu}$ and $\mathrm{La}-\mathrm{Cu}$. It is worth noting that an ambient oxygen pressure much lower than that in the diagram may change the phase diagram of $\mathrm{BaCuO}_{2}$, but probably not that of $\mathrm{BaCu}$.

A simple model of the particulate formation is a melt droplet formation on a target. However, from the phase diagrams, this model is difficult to explain the formation of particulate having composition different from the target materials such as $\mathrm{BaCuO}_{2}$ and, especially, $\mathrm{BaCu}$. As discussed later, the particulates having compositions different from a bulk composition of a target could originate from decomposition and segregation on the target surface.

\section{F. Target material dependence of the deposition rate}

Figures 8(a) and 8(b) show the deposition rates when films were deposited in the same condition using different targets. The abscissa shows $T_{m}$ 's of the target materials. The results demonstrate that the normalized deposition rate can 
be increased by one order of changing the metal source. As $T_{m}$ increased, the normalized deposition rate monotonously decreased for given kinds of compounds: $\mathrm{Cu}$ halides, $\mathrm{Cu}$ chalcogenides, $\mathrm{Ba}$ chalcogenides, and $\mathrm{Y}$ halides. This suggests that the laser deposition process can be regarded as a thermal or suprathermal process as a first approximation.

\section{DISCUSSION}

\section{A. Possible origin of the particulate formation}

PLD process has been usually modeled by a thermal or suprathermal process by assuming a homogeneous heating of target surface, an unchanged target surface morphology, and an unchanged composition during the deposition. ${ }^{20,25}$ By extending this approach, the particulate formation was explained by the subsurface heating effect. ${ }^{26}$ However, there seem also other causes of the particulate formation, because the above assumptions are violated in a usual PLD. If target materials are composed of metal and gas elements, e.g., oxides, their target surfaces would become gas-element deficient by laser heating and finally be decomposed, as shown by $x$-ray photoelectron spectroscopy of YBCO targets. ${ }^{27}$ Change of target surface morphology has been also reported, ${ }^{26,28,29}$ which accompanied change of the target surface composition and its local variation. ${ }^{28,29}$ Additionally, we often observed red-colored $\mathrm{Cu}$ oxides at the peripherals of an irradiated surface area of YBCO targets, Indeed, it is a common practice to use a dense fresh target or a freshly polished target to suppress the particulate formation.

These changes would enhance an inhomogeneous laser heating of the target, and, therefore, both vaporization and liquefaction would occur simultaneously on it during the laser evaporation process. This inhomogeneity model can explain formation of particulate having the composition different from a target material. The observed rapid reduction of relatively large particulates at a low normalized deposition rate may require more complicated explanation: The larger the size of morphological irregularities on the target is, the more the heat is required to melt or to separate them from the target. Indeed, we have observed that the polished $\mathrm{YCu}$ or $\mathrm{YCu}_{3}$ targets yielded more particulates than fresh ones.

The material dependence of the particulate formation is related with difference of optical and thermal properties such as the thermal conductivity and the absorption coefficient. For example, particulates were reported to reduce using densely packed targets ${ }^{18,26}$ and using lasers with a shorter wavelength. 5 The imaginary part of refractive indices $\kappa$ at $193 \mathrm{~nm}(\alpha=2 \kappa / \lambda, \alpha$ :absorption coefficients, $\lambda$ :wavelength) are known only for a few materials. They are not very material-dependent $\left(\alpha \sim 10^{5} \mathrm{~cm}^{-1}\right)$ and are typically $0.6,0.9$, $0.6,1.6,0.7$, and 0.5 for $\mathrm{YBCO}, \mathrm{Ba}, \mathrm{Y}, \mathrm{Cu}, \mathrm{SrTiO}_{3}$, and $\mathrm{BaTiO}_{3}$ near $\mathrm{RT}$, respectively. On the other hand, the thermal conductivity coefficients depend on the preparation and the material. They are approximately $5-10,20,20,370,10$, and $10 \mathrm{~W} \mathrm{~K}^{-1} \mathrm{~m}^{-1}$ for $\mathrm{YBCO}, \mathrm{Ba}, \mathrm{Y}, \mathrm{Cu}, \mathrm{SrTiO}_{3}$, and $\mathrm{BaTiO}_{3}$ near RT, respectively. The thermal conductivity differences can explain the gross material dependence of the deposition rate and of the particulate formation, if we apply the subsurface heating model ${ }^{26}$ to our results. However, they cannot (a)

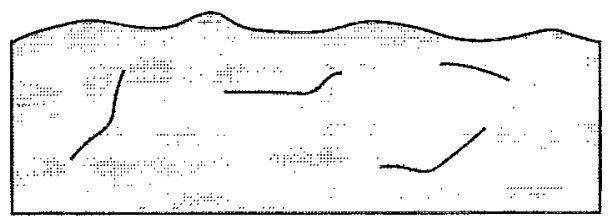

(b)
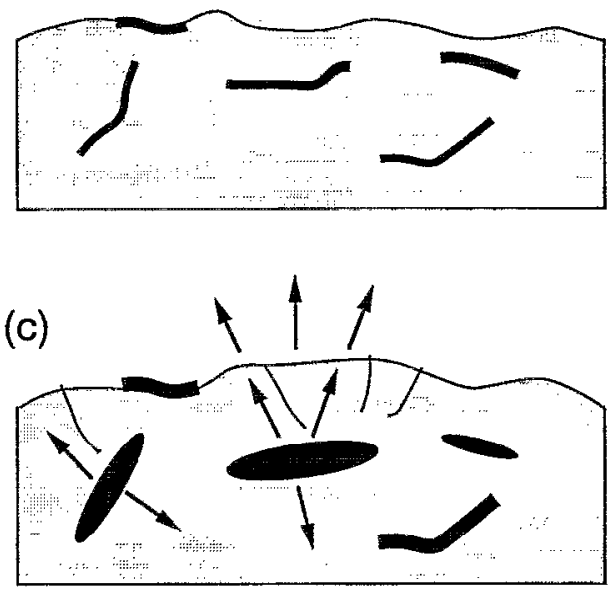

FIG. 9. Particulate formation caused by segregates. (a) Grain boundaries are shown by the thin lines in the target (shaded area). (b) The low- $T_{m}$ metal elements segregate after laser heating as shown by thick lines. (c) These segregates evaporate and expand much faster than matrix and thus exert pressure (arrow) to the matrix to blow off the droplet of the matrix covering them. This can be a model complementary to subsurface heating model (Ref. 26) at a low LPD.

explain why $\mathrm{BaCu}, \mathrm{Ba}: \mathrm{Cu}$ and $\mathrm{YCu}_{x}$ targets yield much more particulate than $\mathrm{Ba}$ and $\mathrm{Y}$ and why mechanically formed $\mathrm{YBa}_{2} \mathrm{Cu}_{3}$ targets do not improve the particulate formation over YBCO targets. Moreover, subsurface heating would be too weak to explain the particulate formation at a low LPD $\left(<1 \mathrm{~J} \mathrm{~cm}^{-2}\right)$.

The conventional PLD process models by a suprathermal process $\mathrm{s}^{20,25}$ can overcome these difficulties, if the effect of inhomogeneity is included. The target materials consisting of high- $T_{m}$ metal elements and low- $T_{m}$ (or volatile) metal elements tended to yield severe particulate problem at the LPD where the film composition became same as that of the target. Examples were $\mathrm{BaCu}, \mathrm{Ba}: \mathrm{Cu}, \mathrm{BaCuO}_{2}, \mathrm{YCuO}_{2.5}$ $\mathrm{BaCuO}_{2}: \mathrm{Y}$, mechanically formed $\mathrm{YBa}_{2} \mathrm{Cu}_{3}, \mathrm{YBCO}$, and $\mathrm{Pb}(\mathrm{Ti}, \mathrm{Zr}) \mathrm{O}_{3}$, with some exceptions, e.g., $\mathrm{BaTiO}_{3}$ and $\mathrm{SrTiO}_{3}$. When these compounds were heated, the partial pressure of the low- $T_{m}$ metals would increase and segregate at the grain boundaries and the surface. Since the target surface is cooling fast, some portion of these segregates would remain after the laser irradiation. If these segregates are located beneath a stoichiometric target material and are heated again by laser pulses, these segregates would vaporize faster than the stoichiometric target material. Consequently, they would blow off droplets or fractions of the stoichiometric 
target material from the surface (Fig. 9). This mechanism would dominate at a low LPD. The observation of the $\mathrm{Cu}$ oxides at the peripherals of the YBCO target surface mentioned above supports this view, together with the following observation by us: $\mathrm{PbO}$ appeared on the $(\mathrm{Pb}, \mathrm{La})(\mathrm{Zr}, \mathrm{Ti}) \mathrm{O}_{3}$ target surface immediately after taken out from a furnace $\left(600-800^{\circ} \mathrm{C}\right)$ and disappeared when cooled. The segregation during PLD was also indirectly supported by the examination of deposit distributions of which details will be discussed elsewhere.

Finally, we would like to comment on the reduction of the precipitates in YBCO films by miscut $\mathrm{SrTiO}_{3}(100)$ or $\mathrm{SrTiO}_{3}(110)$ substrates. It is often observed that the particles having composition different from YBCO arc reduced on the films on these substrate as compared with the films on the $\mathrm{SrTiO}_{3}(100)$. Therefore, these particles were sometimes interpreted as precipitates. This argument would be probably correct for the majority of such particles which have irregular shapes. However, it would be equally possible for particulates to disappear on these miscut substrates at an elevated temperature by diffusing into the matrix. Therefore, it is likely that $\mathrm{CuO}$ or $\mathrm{BaCuO}_{2}$ on the $\mathrm{YBCO}$ films having a semispherical shape is not precipitate but particulate from the targets, considering the discussion in the previous section.

\section{B. Possibility of low power laser PLD}

All halide compounds and most of the sulfide compounds previously mentioned were observed to change into oxides when they were heated in the presence of oxygen. Combining this observation with the material dependence of the normalized deposition rate, we may propose to use these halides or sulfide compounds as metal sources to reactively grow oxide films. This approach allows a significant reduction of the LPD requirement.

\section{Possibility of elimination of particulate}

The present results suggest an approach to eliminate the particulate: Namely, the use of a metal or alloy target consisting of metals having a similar $T_{m}$ to void the segregation and the decomposition due to gas-element reduction, and use of a low normalized deposition rate to suppress the growth of morphological irregularities on the target surface. From a practical viewpoint, a relatively low thermal conductivity and a moderate $T_{m}$ are desirable. These requirements are adequately satisfied by simple metals such as $\mathrm{Ti}, \mathrm{Pb}$, and $\mathrm{Y}$ and almost satisfied by some alloys such as Ti-Zr, $\mathrm{Y}-\mathrm{Cu}$, and $\mathrm{La}-\mathrm{Cu}$. Although the requirements are almost satisfied, some metals such as $\mathrm{Ba}$ metal still yielded particulates after long time use. $\mathrm{Ba}$ is known to form no stable passivation layer. Indeed, its irradiated area exhibited a severe oxidation and the surface roughness. The oxidation and the resulting homogeneity degradation of the Ba surface, i.e., the inhomogeneity of the oxidation and the roughness, would have caused the particulate formation. To overcome this problem, Ba metal was doped with $\mathrm{Cu}$. This approach could suppress the (a)
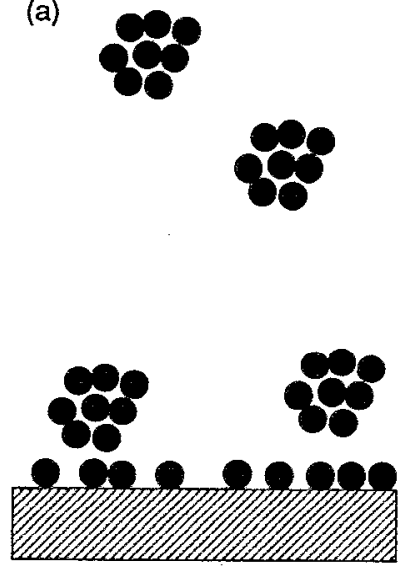

(b)
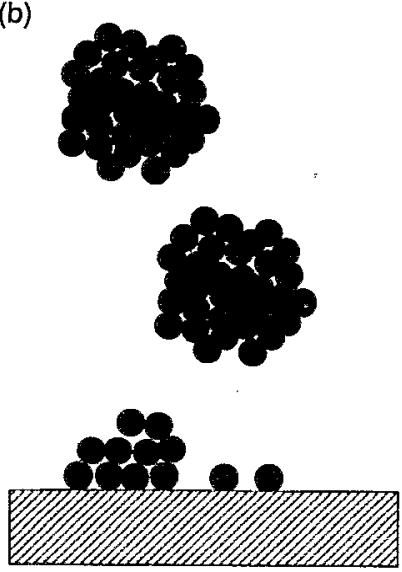

FIG. 10. Migration of adatoms of particulate with different sizes. Binding energy of small particulates is so small that the atoms get apart when it hits the surface (a), contrary to the atoms in large particulates (b).

oxidation but produced another problem: formation of $\mathrm{Cu}$ particulates. At present a fresh $\mathrm{Ba}$ metal seems the only good Ba source in PLD.

This approach to eliminate particulates may be imperfect. However, it can provide only good particulates even if it does still small particulates, because metals and alloys usually have much lower $T_{m}$ 's than oxides. Therefore, their particulates can melt or decompose into atoms when they collide with a heated substrate. For example, $T_{m}$ 's of $\mathrm{YCu}_{3}$ and $\mathrm{Ba}$ are $700-800^{\circ} \mathrm{C}$. They are sufficiently close to $T_{s}$, where YBCO is grown. Moreover, reduction of $T_{m}$ by a size effect is so strong for small clusters that an evaporation energy of the clusters smaller than $\sim 100 \AA \phi$ should be much less than that estimated by thermodynamics. ${ }^{30,31}$ Therefore, they would easily break up into atoms even at RT. Figure 10 summarizes these speculations. It should be noted the diameter of a particulate on a substrate formed by a spherical cluster of $100 \AA \phi$ would be $200-300 \AA \phi$.

Therefore, a complete elimination of a particulate on the heated substrate by this approach can be possible. Pursuing this approach, we have recently proposed a modified version of PLD. This PLD uses multitargets to choose the energy density and the target materials freely, and sequential laser irradiation to control film composition, which enables to eliminate particulates without reducing arrival of excited species at a substrate. ${ }^{13,32}$

\section{CONCLUSION}

Particles in PLD were examined systematically. Their size, number density, areal occupancy, and composition were approximately correlated with the normalized deposition rate, which is the ratio of the laser power density (LPD) to the ablation threshold. At a low normalized deposition rate, the majority of particles had the composition different from the target bulk composition. Based on these observations, we have proposed segregation and decomposition of the target surface during PLD as a particulate formation mechanism at 
a relatively low normalized deposition rate. Finally, a possibility of new PLD's was discussed.

\section{ACKNOWLEDGMENTS}

The authors would like to acknowledge K. Kuriwada for alloy target preparation and Dr. B. Friedrichs for discussion.

${ }^{1}$ See, for example, J. T. Cheung and H. Sankur, CRC Crit. Rev. Solid State Mater. Sci. 15, 63 (1988); J. T. Cheung and J. Horowotz, MRS Bull. 30 (1992).

${ }^{2}$ H. Karl and B. Stritzker, Phys. Rev. Lett. 69, 2939 (1992).

${ }^{3}$ T. Venkatesan, X. D. Wu, R. Muenchausen, and A. Pique, MRS Bull. 54, (1992).

'D. Lubben, S. Barnett, K. Suzuki, S. Gorbatikin, and J. Green, J. Vac. Sci. Technol. B 3, 968 (1985).

${ }^{5}$ R. Ramesh, A. Inam, D. M. Hwang, T. D. Sands, C. C. Chang, and D. L. Hart, Appl. Phys. Lett. 58, 1557 (1991); G. Koren, A. Gupta, R. Baseman, M. Latwyche, and R. Laibowitz, ibid. 55, 2450 (1989).

${ }^{6}$ S. G. Lee, D. S. Hwang, Y. K. Park, and J. C. Park, Appl. Phys. Lett. 65, 764 (1994).

${ }^{7}$ B. Holzaptel, B. Roas, L. Schultz, P. Bauer, and G. Saemann-Ischenko, Appl. Phys. Lett. 61, 483 (1992).

${ }^{8} \mathrm{O}$. Eibl and B. Roas, J. Mater. Res. 5, 2620 (1990).

${ }^{9}$ C. C. Chang, X. D. Wu, R. Ramesh, X. X. Xi, T. S. Ravi, T. Venkatesan, D. M. Hwang, R. E. Munchausen, R. S. Foltyn, and S. Nogar, Appl. Phys. Lett. 57, 1814 (1990).

${ }^{10}$ A. Catana, R. F. Broom, J. G. Bedenorz, J. Mannhart, and D. G. Schlom, Appl. Phys. Lett. 60, 1016 (1992).

${ }^{11}$ A. Catana, J. G. Bedenorz, Ch. Gerber, J. Mannhart, and D. G. Schlom, Appl. Phys. Lett. 63, 553 (1993).

${ }^{12}$ J. Zhao, C. S. Chern, Y. Q. Li, P. Norris, B. Gallois, B. Kear, X. D. Wu, and R. E. Munchausen, Appl. Phys. Lett. 57, 18184 (1990).

${ }^{13}$ Y. Watanabe, Appl. Phys. Lett. 64, 1295 (1994).

${ }^{14} \mathrm{Y}$. Watanabe, Abstract of Applied Superconductivity Conference, MOA-2, Chicago (1992); Y. Watanabe, M. Tanamura, and Y. Seki, Extended Abstracts of the 40th Spring Meeting (in Japanese) (Japan Society of Applied Physics, Tokyo), p. 150; M. Tanamura, S. Matsumoto, Y. Seki, and Y. Watanabe, Extended Abstracts of the 4lst Spring Meeting (in Japanese)
(Japan Society of Applied Physics, Tokyo, 1994), p. 128.

${ }^{15}$ G. Adrian, W. Wilkens, C. Stoelzel, G. Grabe, and V. Windte, IEEE Trans. Appl. Supercond. 3, 1061 (1993).

${ }^{56}$ Y. Watanabe, Y. Matsumoto, H. Kunitomo, M. Tanamura, and E. Nishimoto, Jpn. J. Appl. Phys. 33, 5182 (1994).

${ }^{17}$ T. Venkatesan, X. D. Wu, A. Inam, and J. B. Wachtman, Appl. Phys. Lett. 52, 1193 (1988); A. Inam, X. D. Wu, T. Venkatesan, S. B. Ogale, C. C. Chang, and D. Dijkkamp, ibid. 51, 1112 (1987).

${ }^{18}$ R. K. Singh, D. Bhattacharya, and J. Narayan, Appl. Phys. Lett. 61, 483 (1992).

${ }^{19}$ A. Cohen, P. Allenspacher, M. M. Brieger, I. Jeuck, and H. Opower, Appl. Phys. Lett. 59, 2186 (1991).

${ }^{20}$ R. K. Singh and J. Narayan, Phys. Rey. B 41, 8843 (1990).

${ }^{21}$ S. Katayama, A. Morimoto, T. Shimizu, Y. Yonezawa, K. Segawa, and T. Minamikawa, Extended Abstracts of the 54th Fall Meeting (in Japanese) (Japan Society of Applied Physics, Tokyo, 1993), p. 113.

${ }^{22}$ R. S. Roth, K. L. Davis, and J. R. Dennis, Adv. Ceram. Mater. 2, 303 (1987); B. T. Ahn, V. Y. Lee, R. Beyers, T. M. Gur, and R. A. Huggins, Physica C 167, 529 (1990).

${ }^{23}$ W. Zhang, K. Osamura, and S. Ochiai, J. Am. Ceram. Soc. 73, 1958 (1990).

${ }^{24}$ See, for example, M. Hansen, and K. Anderko, Constitution of Binary Alloys, 2nd ed. (McGraw-Hill, New York, 1958); T. B. Massalski, J. L. Murray, L. H. Bennett, and H. Baker (Eds.) Binary Alloy Phase Diagrams (American Society for Metals, Metals Park, Ohio, 1986).

${ }^{25}$ K. L. Saenger, J. Appl. Phys. 70, 5629 (1991).

${ }^{26}$ R. K. Singh, D. Bhattacharya, and J. Narayan, Appl. Phys. Lett. 57, 2022 (1990).

${ }^{27}$ K. Matsumoto, T. Nakamura, and Y. Watanabe, Mitusbishi Kasei R\&D Rev. 7, 1 (1993) (in Japanese).

${ }^{28}$ S. R. Foltyn, R. C. Dye, K. C. Ott, E. Peterson, K. M. Hubbard, W. Hutchinson, R. E. Muenchausen, R. C. Ester, and X. D. Wu, Appl. Phys. Lett. 59, 594 (1991).

${ }^{29}$ K. H. Young, Physica C 211, 1 (1993).

${ }^{30}$ I. Yamada, G. D. Stein, H. Usui, and Takagi, Proceedings of the 6 th Symposium on Ion Sources and lon-assisted Technology (IEEJ, Tokyo, 1982), p. 47.

${ }^{31}$ T. Takagi, J. Vac. Sci. Technol. A 2, 382 (1984).

${ }^{32}$ H. Asami and Y. Watanabe, Jpn. J. Appl. Phys. 33, L10731 (1994).

${ }^{33}$ Y. Watanabe, M. Tanamura, H. Asami, Y. Matsumoto, Y. Seki, and S. Matsumoto, Physica C 235-240, 579 (1994). 